\title{
PENYELESAIAN SISTEM PERSAMAAN LINEAR DENGAN MATRIKS MENGGUNAKAN PEMROGRAMAN PASCAL (Lokasi Pengabdian: SMAN 1 Kuta Selatan)
}

\author{
I D.M.B.A. Darmawan ${ }^{1}$, L.G. Astuti ${ }^{2}$, K. Sari ${ }^{3}$, I.G.O.G. Atitama ${ }^{4}$, M.A. Raharja ${ }^{5}$
}

\begin{abstract}
ABSTRAK
Pemrograman pascal digunakan untuk menyelesaikan masalah Matematika yang diajarkan pada Siswa SMA sesuai dengan kurikulum yang diajarkan.Pendekatan pelatihan ini memiliki tiga manfaat utama, yaitu: 1) memberikan pengetahuan dan pengalaman kepada siswa SMA terhadap bahasa pemrograman pascal sehingga dapat mempersiapkan diri untuk mengikuti kompetisi-kompetisi yang rutin diselenggarakan oleh Pemerintah dalam Olimpiade Sains Nasional (OSN) atau pun tingkat Regional yang tiap tahun diselenggarakan oleh Universitas Udayana, 2) peningkatan pemahaman materi pelajaran Matematika dengan pendekatan bahasa pemrograman pascal khususnya materi sistem persamaan linear. Bahasa pemrograman melatih siswa untuk dapat berpikir terstruktur dan sistematis. Oleh karena itu, jika siswa telah mampu menyelesaikan masalah Matematika dengan bahasa pemrograman, siswa tersebut sudah benarbenar paham mengenai teknik pemecahan masalah sesuai dengan topik materi yang diberikan. 3) Memberikan alternatif teknik pengajaran yang berbeda kepada Guru Matematika SMA dalam pengajaran menggunakan bahasa pemrograman, dimana pemrograman komputer sangat erat kaitannya dengan pelajaran Matematika.

Pembinaan dihadirkan oleh guru pengampu pelajaran Matematika dan 20 orang siswa. Pembinaan dilakukan selama 4 kali pertemuan dimana setiap pertemuan dilakukan selama 3 jam. Materi yang diberikan meliputi logika informatika dan dasar pemrograman sampai dengan penyelesaian maslaah matematika dengan pemrograman komputer menggunakan bahasa pemrograman Pascal. Setiap pertemuan dilakukan tes diawal dan diakhir yang memperlihatkan kemampuan siswa dalam menyerap materi. Hasil post test memperlihatkan siswa mampu lebih memahami materi matematika setelah mendapatkan pembinaan dalam hal pemrograman komputer sesuai dengan topik yang didiskusikan.
\end{abstract}

Kata kunci: matematika, pemrograman komputer, pascal, tindakan kelas.

\begin{abstract}
Pascal programming is used to solve problems that are taught mathematics at high school students. This training has three major benefits, such as: 1) provide knowledge and experience to high school students against the pascal programming language so it can prepare for the competitions which are regularly held by the Government in the National Science Olympiad (OSN) or regional level are annually organized by the
\end{abstract}

\footnotetext{
1,2,4,5 PS. Teknik Informatika, Fakultas Matematika dan Ilmu Pengetahuan Alam,

Universitas Udayana

Telp/Fax : (0361) 701805, E-mail : dewabayu@cs.unud.ac.id

${ }^{3}$ PS. Matematika, Fakultas Matematika dan Ilmu Pengetahuan Alam,

Universitas Udayana
} 
University of Udayana, 2) improving the understanding of the subject matter of Mathematics with pascal programming language approach. Programming languages train students to be able to think a structured and systematic. Therefore, if the students have been able to resolve the problem of Mathematics with the programming language, the students have really understood the problem-solving techniques in accordance with the material given topic. 3) Provide an alternative for different teaching techniques to the high school mathematics teacher in teaching programming language, where computer programming is very closely related to mathematics.

Guidance is presented by the math teacher and 20 students. Training was done during 4 meetings where every meeting was held for 3 hours. Materials provided include informatics and basic programming logic to completion mathematic problems with computer programming using the Pascal programming language. Each meeting conducted tests that show the beginning and end student's ability to absorb the material. Post test results showed students were able to better understand the mathematical material after getting guidance in programming the computer according to the topics discussed.

Keywords : mathematic, programming language, pascal, training

\section{PENDAHULUAN}

Definisi dari program adalah sebuah pertanyaan umum yang pertama kali diajukan oleh orang yang baru pertama mengenal dunia komputer dan bahasa pemrograman. Pemahaman akan apa itu program bisa kita ilustrasikan dengan kehidupan sehari-hari. Ilustrasi yang paling mudah, adalah bagaimana komunikasi dapat dilakukan oleh orang yang berbeda bahasa dengan anda agar dapat saling bekerjasama. Untuk dapat memahami bahasa yang digunakan oleh orang tersebut, anda harus mempelajari cara membaca huruf, bentuk dan suaranya, cara menuliskan bahasa tersebut dengan aturan yang benar dan valid. Pemahaman terhadap bahasa yang digunakan oleh orang asing tersebut memungkinkan komunikasi dapat dilakukan.

Begitu juga dengan bahasa pemrograman, bahasa pemrograman adalah media untuk berkomunikasi antara pembuat program (dikenal dengan programmer) dengan mesin (komputer). Dengan bahasa pemrograman, pengguna dapat memerintah sebuah komputer untuk melakukan apa yang harus dilakukan. Menuliskan perintah atau intruksi dengan benar dan dimengerti oleh komputer, akan membuat komputer patuh dan melaksanakan semua perintah yang diberikan terus menerus sampai kondisi dimana "dia" harus berhenti.

Komputer adalah sebuah mesin hitung yang dapat bekerja dengan cepat dan tahan lama dibandingkan dengan manusia. Namun, segala kepintaran yang dimilikinya tidak lepas dari logika atau intruksi-intruksi yang diberikan seorang programmer kepada Komputer tersebut. Oleh karena itu kecanggihan suatu komputer yang digunakan saat ini tidak lepas dari semakin berkembangnya ilmu pengetahuan dibidang rekayasa perangkat lunak ataupun kemampuan sumber daya manusia dalam mengembangkan aplikasi yang baik dan berteknologi tinggi. Untuk mempersiapkan tenaga yang terampil dibidang Rekayasa Perangkat Lunak, maka penulis menganggap penting untuk melatih kemampuan pemrograman komputer kepada siswa-siswi SMA. Siswa dengan tingkat SMA dianggap memiliki kemampuan yang mencukupi untuk diberikan pengetahuan mengenai pemrograman komputer, karena dasar ilmu yang harus dimiliki seperti halnya logika matematika telah dipelajari sejak SMP dan SMA.

Berdasarkan hasil kunjungan yang telah dilakukan sebelumnya ke SMA Negeri 1 Kuta Selatan, disampaikan oleh Kepala Sekolah, Drs. I Nyoman Tingkat, M.Hum., kurikulum yang saat ini diterapkan oleh SMA Negeri 1 Kuta Selatan yang masih menggunakan Kurikulum KTSP, materi pemrograman bukan merupakan bagian dari materi wajib yang harus diajarkan kepada siswa

\section{8 | BULETIN UDAYANA MENGABDI}


tingkat Sekolah Menengah Atas (SMA). Berdasarkan kurikulum dasar yang diberikan oleh pemerintah atau Diknas materi yang di pelajari oleh siswa tingkat SMA hanya sebatas pada materi sistem operasi dan penggunaan aplikasi pengolah kata untuk kelas $\mathrm{X}$, materi jaringan dan menggunakan aplikasi pengolah angka untuk kelas XI, serta materi internet dan sedikit pemrograman web untuk siswa kelas XII.

Oleh karena itu, maka wajar apabila materi pemograman Pascal tidak diajarkan karena sesuai dengan kurikulum KTSP pengajaran materi TIK hanya sebatas pengetahuan penggunaan komputer, seperti pengolah kata, jaringan komputer dan desain. Padahal, pendidikan yang terkait dengan teknologi khususnya pemrograman komputer akan merangsang kecerdasan psikomotorik seorang siswa. Pendidikan pemrograman komputer juga dapat melatih daya nalar siswa sehingga memiliki kemampuan yang baik dalam penyelesaian suatu permasalahan. Selain daripada itu, adanya Olimpiade Komputer yang selalu diadakan setiap tahunnya selalu menggunakan soal-soal yang bermaterikan pemograman pascal. Dengan diajarkannya materi ini, diharapkan muncul siswa-siswa yang memiliki kemampuan lebih dalam bidang pemograman pascal untuk dapat diikut sertakan dalam olimpiade. Beberapa manfaat lain yang didapat ketika mengajarkan materi pemograman pascal ini adalah untuk memperkenalkan secara dini bahasa pemograman kepada siswa dan untuk melatih logika berfikir siswa.

Agar dapat menyelesaikan pengabdian dengan baik, anggota dalam pengabdian ini merupakan dosen-dosen yang menguasai dengan baik mengenai permasalahan yang akan diselesaikan yaitu berasal dari Jurusan Ilmu Komputer, Matematika dan Fisika. Oleh karena itu, harapan dari pelaksanaan pengabdian ini adalah selain menghasilkan sumber daya manusia yang siap untuk menghadapi perkembangan teknologi yang pesat dengan penguasaan pemrograman komputer, juga diharapkan dapat membantu proses pemahaman pelajaran Matematika dengan menggunakan pendekatan pemrograman komputer. Sehingga pengabdian yang dilaksanakan akan selaras dengan pendidikan yang diberikan di sekolahnya khususnya pada mata pelajaran Matematika.

\section{PEMECAHAN MASALAH}

Tahapan pemecahan masalah di atas adalah sebagai berikut:

1. Memberikan pengayaan materi Matriks, SPL, dan penyelesaian SPL dengan Matriks. Memaparkan beberapa model permasalahan dengan teknik pemecahan manual. Konsep analitikal dan logika diberikan untuk membangun dasar kemampuan pemecahan masalah.

2. Memberikan penyegaran/pengenalan terhadap materi logika dan sintaks pemrograman dengan bahasa pascal yang telah dilakukan pada pengabdian sebelumnya. Materi akan dimulai dari bentuk pemrograman yang sederhana hingga kompleks sehingga mahasiswa memiliki nalar yang baik dalam konsep pemrograman.

3. Pelatihan penyelesaian-penyelesaian SPL dengan matriks dengan cara menerapkan kedalam bahasa pemrograman pascal. Pada bagian ini akan menyelesaikan permasalahanpermasalahan yang sebelumnya diselesaikan dengan manual menjadi kode program.

4. Evaluasi proses pelatihan dengan memberikan permasalahan baru dengan tingkat sederhana hingga kompleks sehingga dapat mengetahui proses peningkatan pemahaman siswa setelah menggunakan bahasa pemrograman komputer pada proses pembelajaran mata pelajaran Matematika 


\section{METODE PELAKSANAAN}

\subsection{Metode Pelaksanaan}

Metode yang digunakan dalam kegiatan ini adalah berupa pelatihan bahasa pemrograman pascal, berupa tutorial, diskusi, presentasi dan praktik pengerjaan soal oleh peserta pelatihan. Metode pelaksanaan mengacu pada Arikunto, Suharsimi, 2007 yang diperlihatkan pada Gambar 1.

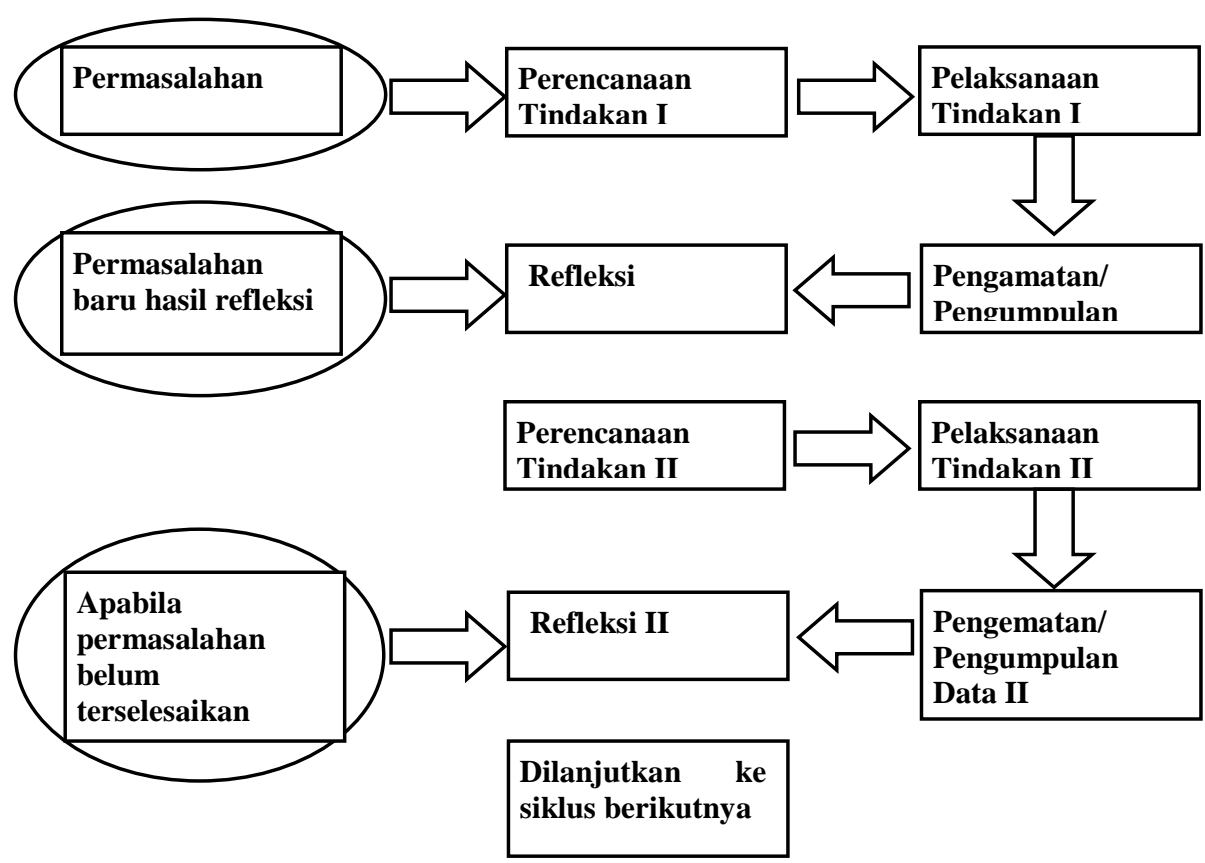

Gambar 1. Alur Penelitian Tindakan Kelas

(dalam Suharsimi Arikunto, Suhardjono, Supardi, 2006: 74)

\subsection{Rencana Evaluasi}

Rencana evaluasi kegiatan pengabdian ini dirancang sebagai berikut:

1. Melakukan pre-test untuk melihat kemampuan siswa sebelum dilaksanakan pelatihan. Hal ini sangat penting untuk dapat merencanakan strategi pembelajaran yang tepat berdasarkan kemampuan siswa. Materi pre-test meliputi pemahaman siswa terhadap materi pemrograman dasar, Matriks dan SPL.

2. Sebagai indikator keberhasilan pengabdian atau pembinaan ini akan terlihat dari peningkatan pemahaman siswa terhadap materi SPL dan Matriks dan juga kemampuan pemrograman pascal. Hal ini dapat diperlihatkan dengan hasil evaluasi yang dilakukan diakhir pembinaan/pengabdian dilaksanakan. 
3. Evaluasi keberhasilkan pengabdian ini juga dilakukan dengan cara evaluasi quisioner yang berisi kritik dan saran dari peserta terhadap proses jalannya pengabdian/pembinaan yang telah dilaksanakan.

\section{HASIL DAN PEMBAHASAN}

\subsection{Perencanaan}

Pada tahap ini dilakukan pertemuan dengan kepala sekolah Sma Negeri 1 Kuta Selatan dan Guru yang membidangi mata pelajaran TIK dan Matematika. Dari pertemuan tersebut didapatkan materimateri yang dapat diberikan dan disesuaikan untuk dapat diberikan menggunakan pendekatan Bahasa pemerograman.

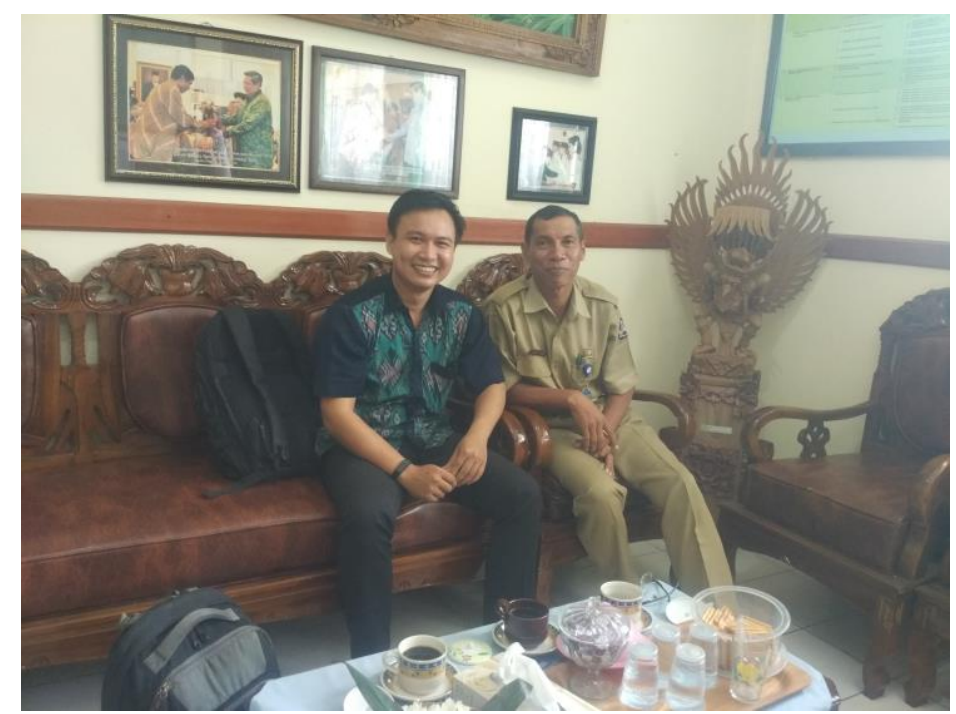

Gambar 2. Koordinasi Pelaksana Pengabdian bersama Kepala Sekolah SMA N 1 Kuta Selatan

Adapun yang menjadi panduan dalam penyusunan modul Bahasa pemrograman untuk meningkatkan pemahaman mata pelajaran matematika kelas $\mathrm{X}$ adalah menggunakan buku matematika berdasarkan Kurikulum 2013. Adapun pertemuan yang kami rencanakan untuk dapat melaksanakan pengabdian ini dengan baik adalah sebagai berikut:

1. Pertemuan I : Pemberian materi mengenai Logika Informatika dan Pemrograman Pascal.

2. Pertemuan II: Pemberian materi mengenai Pemrograman Pascal untuk Persamaan Linear 2 Variabel

3. Pertemuan III: Pemberian materi mengenai Pemrograman Pascal untuk Persamaan Linear 3 Variabel Metode Determinan 
4. Pertemuan IV: Pemberian materi mengenai Pemrograman Pascal untuk Persamaan Linear 3 Variabel Metode Gauss Jordan

Dalam setiap pertemuan dilakukan evaluasi terhadap kemampuan siswa dalam menerima ilmu yang telah diberikan dan melihat efektifitas pemberian pemrograman pascal terhadap pemahaman siswa terhadap permasalahan matematika.

\subsection{Pelaksanaan Tindakan}

Tim Pengabdian telah melaksanakan kegiatan pengabdian baik pada taham perencaan yang menghasilkan modul, soal untuk pretest dan posttest sampai dengan pengabdian di lokasi pengabdian. Pengabdian dalam bentuk bimbingan atau pembinaan dilakukan selama 4 kali pertemuan yaitu pada tanggal 27,29 September 2017 dan 4, 6 November 2017.

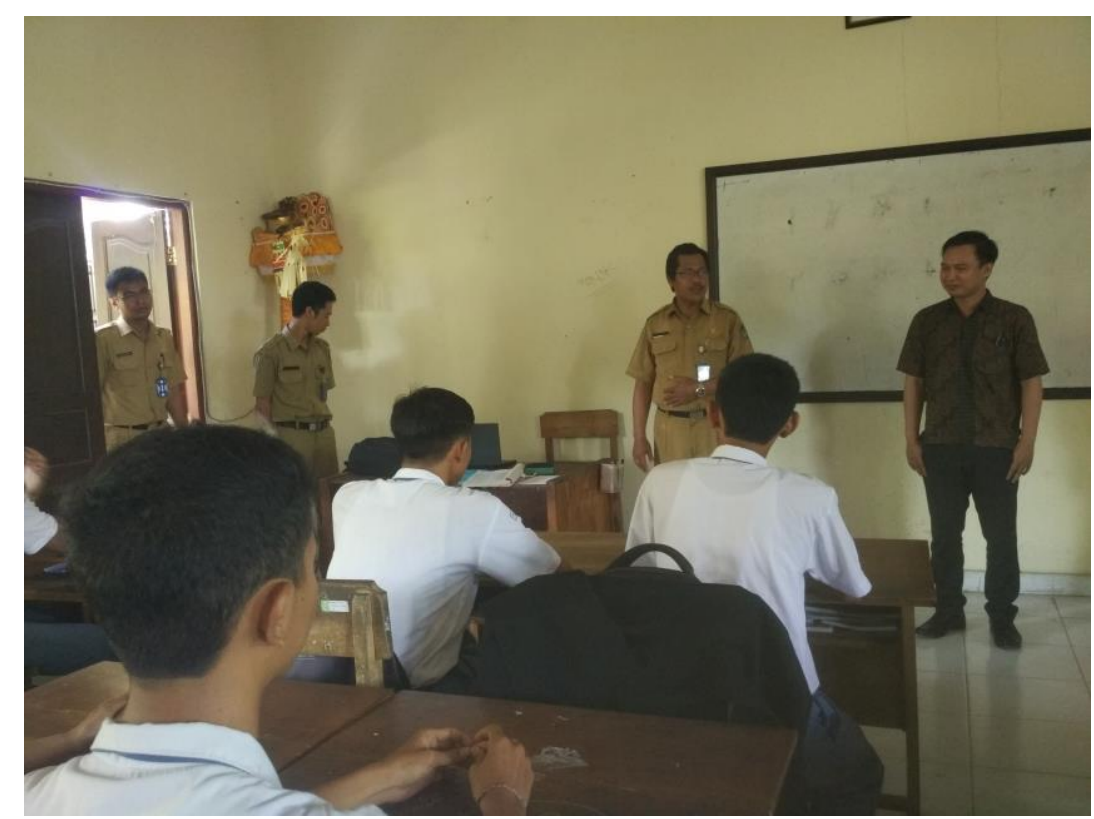

Gambar 3. Pembukaan Kegiatan Oleh Wakasek Kurikulum didampingi oleh Beberapa Guru Terkait 


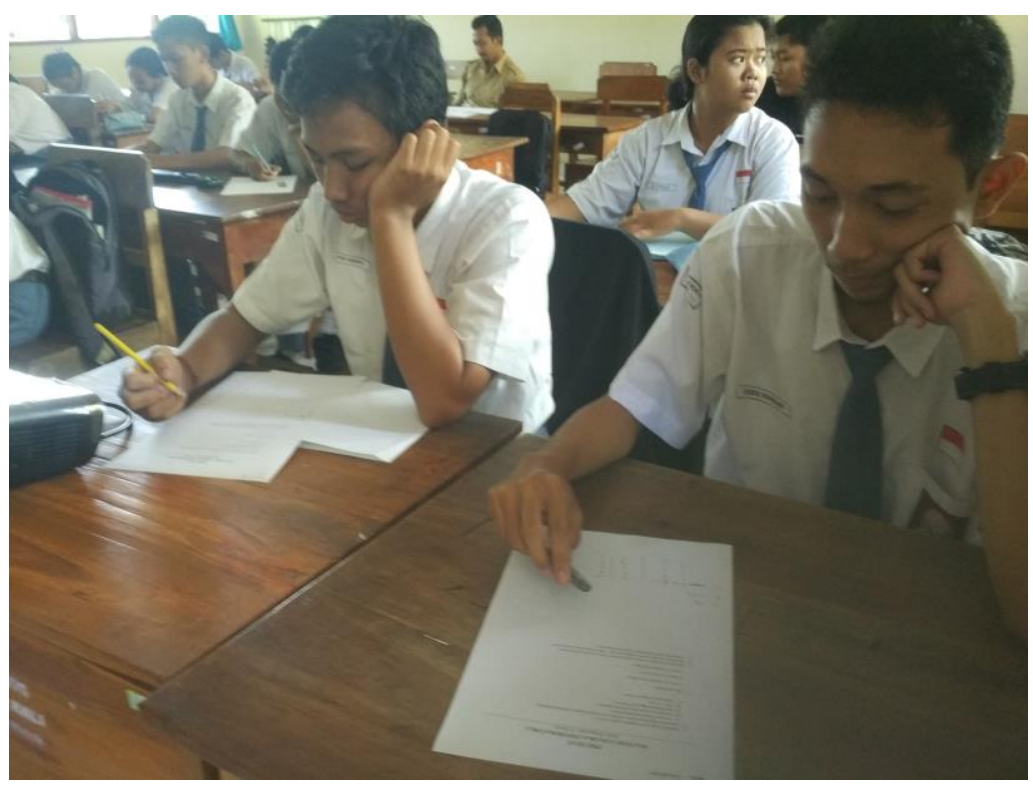

Gambar 4. Pengerjaan Pre Test oleh Siswa

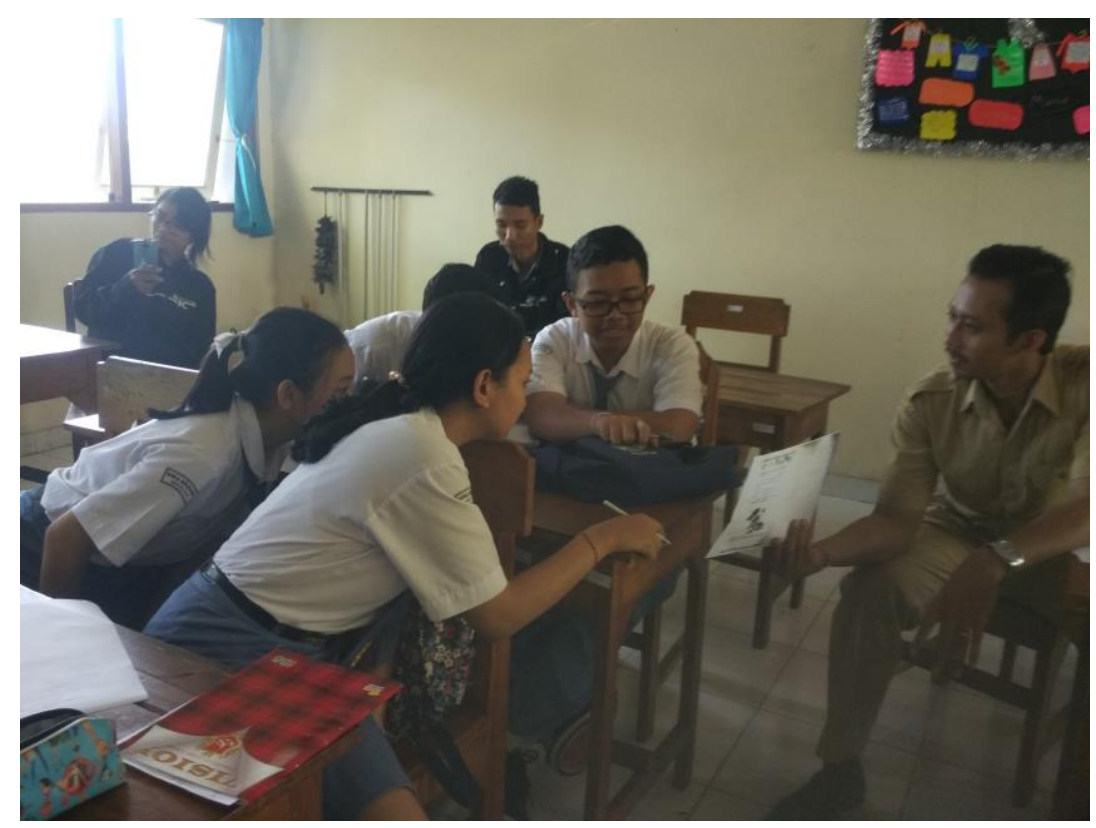

Gambar 5. Diskusi Antara Guru dan Siswa didampingi dengan Mahasiswa Tim Pengabdian 


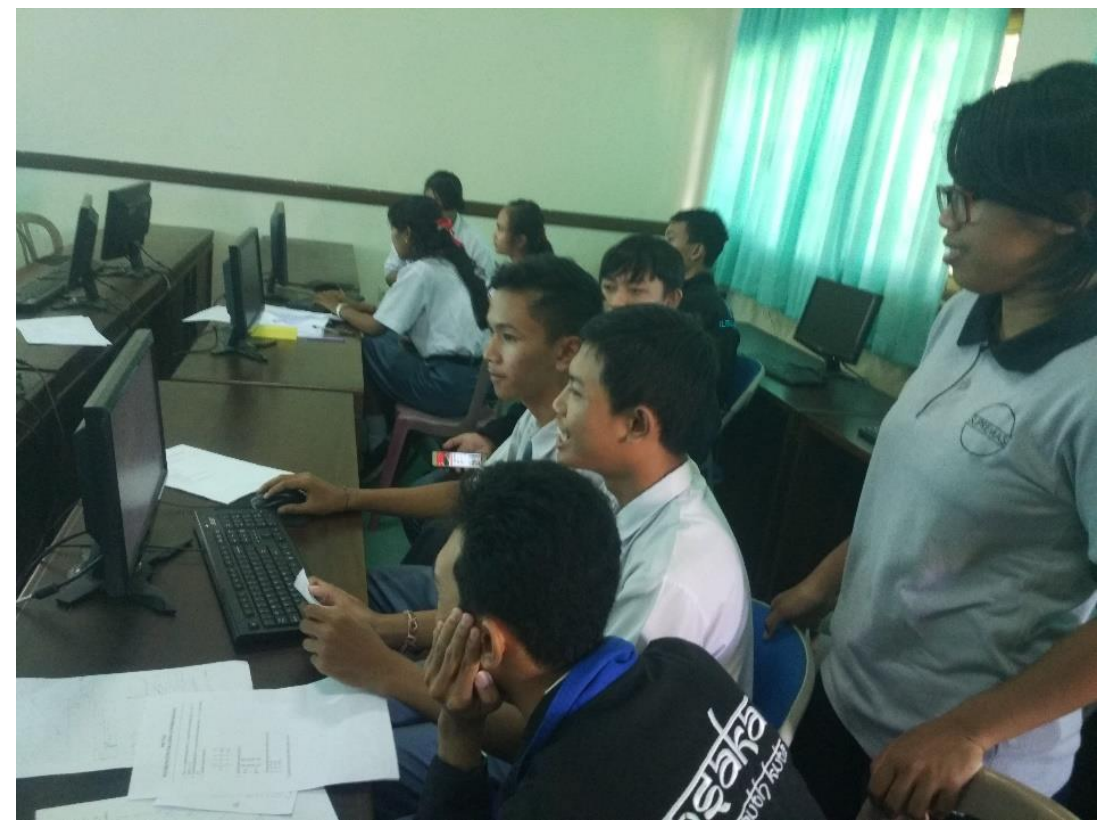

Gambar 6. Keterlibatan Aktif Tim Pengabdian dari Mahasiswa

\subsection{Pengamatan dan Observasi}

Berdasarkan hasil test yang telah dilakukan terlihat peningkatan pemahaman terhadap materi yang telah disampaikan setelah pemberian materi. Siswa lebih mudah memahami materi dengan pendekatan pemrograman komputer.

\subsection{Refleksi}

Tidak ditemukan adanya masalah pada siklus pembelajaran yang telah dilakukan. Namun, perlu ada penekanan materi dasar pemrograman yang baik diawal proses pembelajaran. Hal ini dibutuhkan karena akan memudahkan siswa dalam memahami cara berpikir yang logis dan sistematis sehingga memudahkan siswa untuk membangun algoritma sesuai dengan kasus yang diberikan.

\section{KESIMPULAN}

Peningkatan pemahaman siswa terhadap materi matematika dapat ditingkatkan dengan memberikan pendekatan pemrograman computer dalam membahas materi tersebut. Pemrograman computer akan membuat siswa berpikir secara logis dan sistematis yang dibutuhkan untuk menyelesaikan masalah-masalah matematika. Pemberian materi pemrograman mulai usia dini sangat dibutuhkan, sehingga pengetahuan dasar sudah dimiliki ketika tingkat SMA. Hal ini harus dilakukan mengingat teknologi yang berkembang pesat saat ini dan penggunaan teknologi software sudah sangat umum digunakan oleh anak-anak. Oleh karena itu saran dari pengabdian ini adalah perlu dilakukan pengabdian pada tingkat yang lebih rendah seperti SD ataupun SMP. Namun, dengan pendekatan yang sesuai dengan jenjang pendidikannya.

\section{Ucapan Terimakasih}

\section{4 | BULETIN UDAYANA MENGABDI}


Ucapan terimakasih disampaikan kepada Universitas Udayana melalui Lembaga Penelitian dan Pengabdian Kepada Masyarakat yang telah membiayai pelaksanaan pengabdian ini,dan kepada SMA Negeri 1 Kuta Selatan yang telah bekerjasama dengan baik sehingga pengabdian dapat berjalan dengan baik.

\section{DAFTAR PUSTAKA}

Aqib,Zaenal.2006. Penelitian Tindakan Kelas. Bandung :Yrama Widya

As'ari, A.R. 2003. Strategi Pemecahan Masalah Dalam Pembelajaran Matematika di Sekolah. Makalah disajikan dalam rangka Lomba Matematika Nasional XV dan Lokakarya Guru oleh Himpunan Mahasiswa Matematika Universitas Gadjah Mada, Yogyakarta, 22 Maret 2003. Yogyakarta: UGM.

Depdiknas. 2006. Permendikas Nomor 22 Tahun 2006 Tentang Standar Isi Sekolah Dasar. Jakarta: Depdiknas.

Hasbi, M. 2003. Struktur Data Dan Algoritma Dalam Pemrograman Turbo Pascal, Gava Media, Yogyakarta.

Keeves, J.P. 1992. The IEA technical handbook. Hague : The International Association for the Evaluation of Educational Achiement (IEA).

Pusat Kurikulum. 2002. Kurikulum dan Hasil Belajar Matematika Sekolah Menengah Atas. Jakarta: Depdiknas.

Suharsimi, Arikunto. Penelitian Tindakan Kelas. Jakarta: Bumi Aksara 